\title{
TOPOLOGICAL AND REACTIVITY DESCRIPTOR OF CARISOPRODOL FROM DFT AND MOLECULAR DOCKING APPROACH
}

\author{
Tarun Chaudhary $^{1}$, Manoj Kumar Chaudhary ${ }^{1,2}$, Bhawani Datt Joshi ${ }^{3^{*}}$ \\ ${ }^{I}$ Central Department of Physics, Tribhuvan University, Kirtipur, Kathmandu, Nepal \\ ${ }^{2}$ Department of Physics, University of Lucknow, Lucknow-226007, India \\ ${ }^{3}$ Department of Physics, Siddhanath Science Campus, Tribhuvan University, Mahendranagar, 10406, Nepal \\ "Corresponding author: bhawani.joshi@snsc.tu.edu.np,pbdjoshi@gmail.com
}

(Received: February 05, 2021; Revised: June 01, 2021; Accepted: June 08, 2021)

\begin{abstract}
This study aims to investigate the optimized structure and optimized parameters of carisoprodol from the DFT/B3LYP/6$31 \mathrm{G}(\mathrm{d}, \mathrm{p})$ level of theory. The molecular electrostatic potential (MEP) map signifies that the positive potential across hydrogen of the amine group $\left(\mathrm{NH}_{2}\right)$ and the negative potential around the carbonyl groups $(\mathrm{C}=\mathrm{O})$. HOMO-LUMO energy gap was found to be $8.1064 \mathrm{eV}$. The global and local reactivity parameters describe the possible chemical reactive sites in the molecule. The topological analysis of the electron localization function (ELF) and localized orbital locator (LOL) revealed that the charge localization around hydrogen atoms. The hyper-conjugative interaction between donor and acceptor orbital showed that the interaction $\mathrm{LP}(2) \mathrm{O} 4 \rightarrow \sigma^{*}(\mathrm{O} 2-\mathrm{C} 16)$ plays a vital role in the molecular stability. The molecular docking simulation encircles that the carisoprodol behaves as a good inhibitor with the target protein, Tyrosine-protein kinase ABL.
\end{abstract}

Keywords: Carisoprodol, Electrostatic potential, Energy gap, Orbital locator, Molecular docking

\section{INTRODUCTION}

Carisoprodol $\left(\mathrm{C}_{12} \mathrm{H}_{24} \mathrm{~N}_{2} \mathrm{O}_{4}\right)$, chemically known as (RS)-2$\{[($ aminocarbonyl)oxy]methyl $\}-2$-methyl pentyl isopropyl carbamate is a centrally acting muscle-skeletal relaxant (Reeves et al., 1999). It is used to treat a craniomandibular disorder, sciatica, lumbago, and other lower back syndromes (Kumar et al., 2017; Horio et al., 2004). Literature reveals that the recent works on carisoprodol were mainly focused on its physical, chemical, and biological properties. Bolattin et al. (2016) studied biomolecular interactions of carisoprodol with bovine serum albumin by fluorescence and UV-visible spectroscopy along with a molecular docking approach. Further, the thermal behavior and dynamic fragility in its amorphous state were studied by Diogo et al. (2018).

Recently, Liu et al. (2020) studied the binding activity of carisoprodol on GABA (Gamma-Aminobutyric Acid) receptor by both docking and molecular dynamics (MD) simulation methods. Chaudhary et al. (2021a) performed AIM analysis and investigated vibrational spectra and the nonlinear optical (NLO) properties of the title molecule. However, the structural and spectroscopic properties like calculation of optimized parameters, NBO analysis, HOMO and LUMO energies, MEP, global and local reactivity, the electron localization function (ELF), and the localized orbital locator (LOL) have not been conducted so far. Hence, the present work is mainly concentrated to explore these properties to study the chemical and biological activities of the molecule. The calculations have been performed by using the functional
B3LYP/6-31G (d,p) and the result is closer to the experimental one (Horio et al., 2004).

\section{MATERIALS AND METHODS}

The quantum mechanical study of carisoprodol was performed using the Gaussian 09 program package (Frisch et al., 2009). The geometry was optimized through density functional theory (DFT) calculation by employing the functional B3LYP/6-31G(d,p) (Becke, 1993; Parr \& Yang, 1989). The GaussView 05 program was used to visualize and interpret the output data of Gaussian 09. It was used to plot HOMO, LUMO, and MEP maps. Furthermore, Multiwfn 3.4.1 (Lu \& Chen, 2012) and VMD 1.9.1 (Humphrey et al., 1996) program packages were used for computation and visualization of ELF (electron localization function) and LOL (localized molecular orbital). The molecular docking of carisoprodol has been carried out with AutoDock-Vina software (Trott \& Olson, 2010) and ligand-protein interaction has been visualized with bio visualizer software (Studio, 2009).

To determine the chemical reactivity of carisoprodol, molecular electrostatic potential map, the energy of the highest occupied molecular orbital $\left(\mathrm{E}_{\mathrm{H}}\right)$ and the lowest occupied molecular orbital $\left(E_{L}\right)$, energy gap $\left(E_{L}-E_{H}\right)$, global reactivity, and local reactivity descriptors have been calculated. The molecular electrostatic potential V(r) (Sjoberg et al., 1990) which is used to generate MEP was calculated using the equation (1).

$$
V(r)=\sum_{A} \frac{Z_{A}}{\left|\overrightarrow{R_{A}}-\vec{r}\right|}-\int \frac{\rho\left(\overrightarrow{r^{\prime}}\right)}{\left|\overrightarrow{r^{\prime}}-\vec{r}\right|}
$$


Where, $Z_{A}$ and $\rho\left(\overrightarrow{r^{\prime}}\right)$ are nuclear charge and electron density respectively.

The chemical potential $(\mu)$ of a system is the first-order partial derivatives of energy (E) for the number of electrons $(\mathrm{N})$ at constant external potential $\mathrm{V}(\mathrm{r})$.

$$
\mu=\left(\frac{\partial E}{\partial N}\right)_{V(r)}=-\chi
$$

The words hardness ( $\eta$ ) and softness (S) were first introduced by Pearson to check the direction of the acidbase reaction as well as to gain the stability of the product. From the Koopmans theorem, $\eta$ is half of the energy gap between HOMO and LUMO which signifies to bear the resistance of the system to take or give up electrons. The global hardness which is the inverse of softness is the second-order derivative of energy (E) concerning the number of electrons $(\mathrm{N})$ at constant external potential $\mathrm{V}(\mathrm{r})$.

$$
\eta=\frac{1}{2}\left(\frac{\partial^{2} E}{\partial N^{2}}\right)_{V(r)}=\frac{1}{2}\left(\frac{\partial \mu}{\partial N}\right)_{V(r)}
$$

Electrophilicity index $(\omega)$ is introduced by Parr and Pearson (1983) which is a global reactivity descriptor. It is the characteristics of atoms that include the reduction of energy procedure during the absorption of electrons from the donors. The chemical reactivity of the molecule is analyzed in terms of electrophilicity index $(\omega)$. It measures the stabilization in energy as the molecule gain external electronic charge from neighboring donor species.

Global reactivity descriptor is used to determine the reactivity of a molecule. Koopman's theorem described the global reactivity parameters like electronegativity $(\chi)$, chemical potential $(\mu)$, hardness $(\eta)$, electrophilicity index $(\omega)$ and softness (S) are estimated using the equations (4)(9) (Parr \& Pearson, 1983; Joshi, 2016).

$$
\begin{aligned}
& \chi=-\frac{1}{2}\left(E_{L}+E_{H}\right) \\
& \mu=-\chi=\frac{1}{2}\left(E_{L}+E_{H}\right) \\
& \eta=\frac{1}{2}\left(E_{L}-E_{H}\right) \\
& S=\frac{1}{2 \eta} \\
& \omega=\frac{\mu^{2}}{2 \eta} \\
& \Delta N \max =-\frac{\mu}{\eta}
\end{aligned}
$$

Here, $\omega$ measures the stabilization energy after the system gains the extra charge $(\Delta \mathrm{N})$ from neighboring molecules and $\Delta \mathrm{N}_{\max }$ is the maximum charge gained by electrophile (Parr et al., 1999). Fukui functions help to predict the particular site for the chemical activity. The high values of
Fukui functions $\mathrm{f}(\mathrm{r})$ indicate the high reactivity (Yang \& Parr., 1985). The Fukui functions $\mathrm{f}_{\mathrm{A}}^{+}(\mathrm{r}), \mathrm{f}_{\mathrm{A}}^{-}(\mathrm{r})$ and $\mathrm{f}_{\mathrm{A}}{ }^{0}(\mathrm{r})$ corresponds to the nucleophilic, electrophilic, and radial attacks respectively. The given Fukui equations for the nucleophilic, electrophilic, and radial attack are:

$f_{A}^{+}(r)=\left[q_{A}(N+1)-q_{A}(N)\right]$
$f_{A}^{-}(r)=\left[q_{A}(N)-q_{A}(N-1)\right]$
$f_{A}^{0}(r)=\frac{1}{2}\left[q_{A}(N+1)-q_{A}(N-1)\right]$

Where, $\mathrm{q}_{\mathrm{A}}$ is an atomic charge of the $\mathrm{A}^{\text {th }}$ atomic site corresponding to neutral $(\mathrm{N})$, anionic $(\mathrm{N}+1)$, or cationic $(\mathrm{N}-1)$ chemical state of the molecule.

To interpret the charge delocalization in a molecule, NBO analysis had been performed using the same level of theory. The given equation which is based on secondorder perturbation theory was used to compute the stabilization energy (E2) between the donor and the acceptor groups (Prajapati et al., 2016; Reed et al., 1988):

$E(2)=E(i, j)=q_{i} \frac{F_{i j}^{2}}{\left(E_{j}-E_{i}\right)}$

Where, $\mathrm{q}_{\mathrm{i}}, \mathrm{E}_{\mathrm{i}}, \mathrm{E}_{\mathrm{j}}$, and $\mathrm{F}_{\mathrm{ij}}$ are donor orbital occupancy, donor orbital energy, acceptor orbital energy, and offdiagonal elements of the Fock-matrix, respectively.

\section{RESULTS AND DISCUSSION}

\section{Geometrical parameters}

The geometry of carisoprodol was fully optimized at the DFT-B3LYP level using a 6-31G(d,p) basis set. The optimized structure of carisoprodol is shown in Fig. 1. The comparative study of optimized parameters (bond lengths, bond angles, and dihedral angles) with the geometry of crystal structure (Horio et al., 2004) has been presented in Table 1. Almost all the calculated values are approximately equal to its crystal structure parameters.

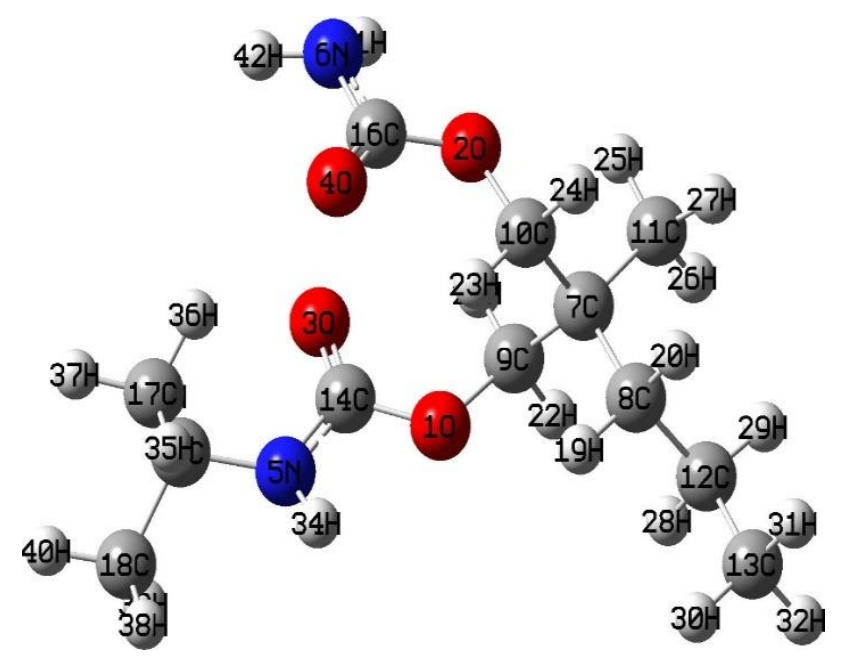

Fig. 1. Optimized structure of carisoprodol 
The calculated values of bond lengths N5-H34, N6-H41, and $\mathrm{N}-\mathrm{H} 42$ are $0.891,0.966$, and $0.779 \AA$, whereas their respective crystal structure values are 1.011, 1.010, and $1.009 \AA$ A. Similarly, the optimized bond angles (C14-N5$\mathrm{H} 34)$, (C15-N5-H34), and (C16-N6-H41) are calculated as $116.16^{\circ}, 118.46^{\circ}$ and $116.38^{\circ}$, and the crystal structure values are $113.07^{\circ}, 107.86^{\circ}$ and $119.34^{\circ}$, respectively. The difference in structural parameters is due to the intermolecular hydrogen bonding in solid form. However, this work is based on computational evaluation for a single isolated molecule in the gaseous state.

\section{Molecular electrostatic potential}

The molecular electrostatic potential (MEP) map is an important tool to explain the chemical reactivity, hydrogen bonding, and structural activity of different biomolecules including drugs (Joshi et al., 2014). Based on the mapped potential energy surface, the relative polarity of molecule, chemically reactive sites can be predicted. On the MEP, the red surface shows the most electronegative region and the blue surface shows the most positive region.

Table 1. Selected optimized parameters of carisoprodol

\begin{tabular}{|c|c|c|c|c|c|}
\hline Bond length $(\AA)$ & Crystal & Calculated & Bond angles $\left({ }^{\circ}\right)$ & Crystal & Calculated \\
\hline (O1,C9) & 1.448 & 1.440 & $(\mathrm{C} 9, \mathrm{O} 1, \mathrm{C} 14)$ & 115.06 & 116.91 \\
\hline$(\mathrm{O} 1, \mathrm{C} 14)$ & 1.360 & 1.369 & $(\mathrm{C} 14, \mathrm{~N} 5, \mathrm{C} 15)$ & 121.70 & 122.16 \\
\hline$(\mathrm{O} 2, \mathrm{C} 10)$ & 1.450 & 1.440 & $(\mathrm{C} 14, \mathrm{~N} 5, \mathrm{H} 34)$ & 113.07 & 116.16 \\
\hline$(\mathrm{O} 2, \mathrm{C} 16)$ & 1.343 & 1.362 & $(\mathrm{C} 15, \mathrm{~N} 5, \mathrm{H} 34)$ & 107.86 & 118.46 \\
\hline$(\mathrm{O} 3, \mathrm{C} 14)$ & 1.214 & 1.221 & $(\mathrm{C} 16, \mathrm{~N} 6, \mathrm{H} 41)$ & 119.34 & 116.38 \\
\hline$(\mathrm{O} 4, \mathrm{C} 16)$ & 1.222 & 1.218 & $(\mathrm{C} 16, \mathrm{~N} 6, \mathrm{H} 42)$ & 115.86 & 113.88 \\
\hline (N5,C14) & 1.379 & 1.359 & (H41,N6,H42) & 124.73 & 115.72 \\
\hline (N5,C15) & 1.445 & 1.465 & $(\mathrm{O} 2, \mathrm{C} 10, \mathrm{C} 7)$ & 108.71 & 110.30 \\
\hline (N5,H34) & 0.891 & 1.011 & $(\mathrm{O} 2, \mathrm{C} 10, \mathrm{H} 23)$ & 107.56 & 108.72 \\
\hline (N6,C16) & 1.348 & 1.368 & $(\mathrm{O} 1, \mathrm{C} 13, \mathrm{O} 3)$ & 124.93 & 124.62 \\
\hline (N6,H41) & 0.966 & 1.010 & $(\mathrm{O} 1, \mathrm{C} 13, \mathrm{~N} 5)$ & 109.66 & 109.58 \\
\hline (N6,H42) & 0.779 & 1.009 & $(\mathrm{O} 3, \mathrm{C} 13, \mathrm{~N} 5)$ & 125.35 & 125.78 \\
\hline$(\mathrm{C} 7, \mathrm{C} 9)$ & 1.550 & 1.539 & $(\mathrm{~N} 5, \mathrm{C} 15, \mathrm{C} 17)$ & 110.85 & 111.24 \\
\hline \multicolumn{2}{|c|}{ Dihedral Angles $\left({ }^{\circ}\right)$} & Crystal & \multicolumn{2}{|c|}{ Calculated } & \\
\hline \multicolumn{2}{|c|}{$(\mathrm{C} 8, \mathrm{C} 12, \mathrm{C} 13, \mathrm{H} 30)$} & 58.53 & \multicolumn{2}{|c|}{59.7365} & \\
\hline \multicolumn{2}{|c|}{$(\mathrm{C} 8, \mathrm{C} 12, \mathrm{C} 13, \mathrm{H} 31)$} & -50.69 & \multicolumn{2}{|c|}{-60.066} & \\
\hline \multicolumn{2}{|c|}{$(\mathrm{H} 28, \mathrm{C} 12, \mathrm{C} 13, \mathrm{H} 31)$} & 177.50 & \multicolumn{2}{|c|}{177.8358} & \\
\hline \multicolumn{2}{|c|}{$(\mathrm{H} 29, \mathrm{C} 12, \mathrm{C} 13, \mathrm{H} 31)$} & 66.77 & \multicolumn{2}{|c|}{62.1842} & \\
\hline \multicolumn{2}{|c|}{$(\mathrm{C} 18, \mathrm{C} 15, \mathrm{C} 17, \mathrm{H} 35)$} & 63.98 & \multicolumn{2}{|c|}{59.0411} & \\
\hline \multicolumn{2}{|c|}{$(\mathrm{C} 18, \mathrm{C} 15, \mathrm{C} 17, \mathrm{H} 36)$} & 178.09 & \multicolumn{2}{|c|}{179.0676} & \\
\hline \multicolumn{2}{|c|}{$(\mathrm{C} 18, \mathrm{C} 15, \mathrm{C} 17, \mathrm{H} 37)$} & -56.33 & \multicolumn{2}{|c|}{-60.0656} & \\
\hline \multicolumn{2}{|c|}{$(\mathrm{C} 18, \mathrm{C} 15, \mathrm{C} 17, \mathrm{H} 35)$} & 63.98 & \multicolumn{2}{|c|}{59.0411} & \\
\hline
\end{tabular}

Further, the lighter color or almost white surface explains the non-polar nature of molecules. The MEP counter map of carisoprodol is shown in Fig. 2 which demonstrates negative regions over $\mathrm{O} 3$ and $\mathrm{O} 4$ and positive regions over H34, H41, and H42. The region over oxygen of carbonyl groups, $\mathrm{C} 14=\mathrm{O} 3$ and $\mathrm{C} 16=\mathrm{O} 4$ are almost equal whereas the region over hydrogen (H41 and H42) of primary amine are comparatively more positive than the region over hydrogen of secondary amine (H34). The molecular docking analysis shows that the atoms $\mathrm{O} 1, \mathrm{O} 2$,
O3, and $\mathrm{O} 4$ actively participated in hydrogen bonding with the protein during the ligand-protein interaction.

\section{HOMO-LUMO analysis}

The chemical stability of molecules depends upon the energy of the highest occupied molecular orbital (HOMO) and the lowest unoccupied molecular orbital (LUMO). The orbital energy HOMO $\left(\mathrm{E}_{\mathrm{H}}\right)$ acts as the electron donor and the orbital energy LUMO $\left(\mathrm{E}_{\mathrm{L}}\right)$ acts as the electron acceptor and their energy gap $\left(\mathrm{E}_{\mathrm{L}}-\mathrm{E}_{\mathrm{H}}\right)$ determines the 
chemical reactivity of the molecule (Chaudhary et al., 2021b; Joshi et al., 2018). The probability of electronic transition activity increases with the increase in the energy gap and vice-versa (Fukui, 1982). To understand the chemical stability of carisoprodol, time-dependent DFT calculations have been performed employing the B3LYP/6-31G (d, p) level of theory. The energy gap for carisoprodol is obtained as $8.1064 \mathrm{eV}$. The HOMOLUMO plot of the molecule shown in Fig. 3 signifies that the electron density in HOMO is concentrated on $\mathrm{O} 1$, $\mathrm{C} 14=\mathrm{O} 3$, and $\mathrm{N} 5 \mathrm{H} 34$ whereas the charge diverges on $\mathrm{C} 16=\mathrm{O} 4$ and $\mathrm{N}_{6} \mathrm{H}_{2}$ in LUMO.

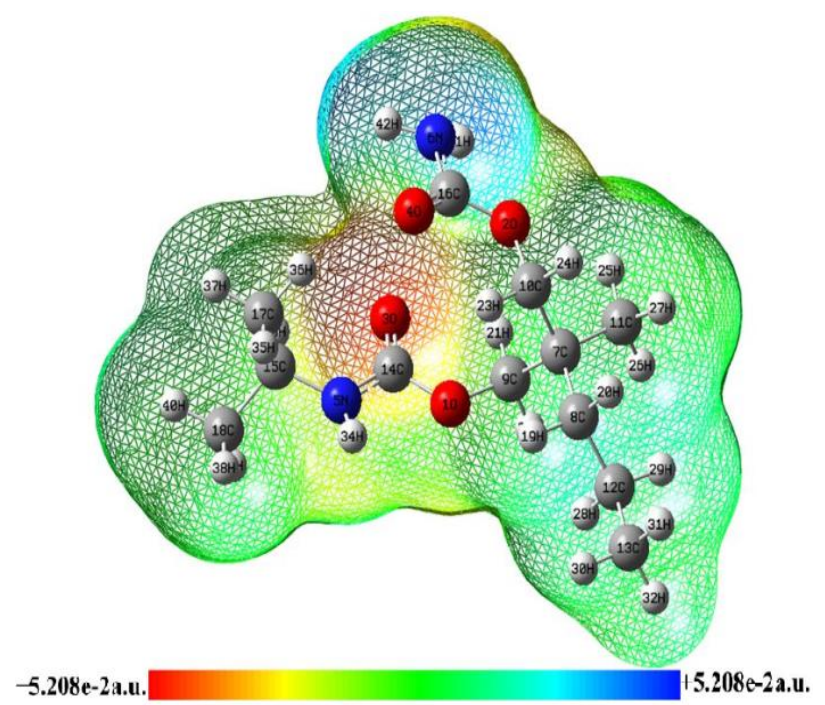

Fig. 2. Molecular electrostatic potential map of carisoprodol

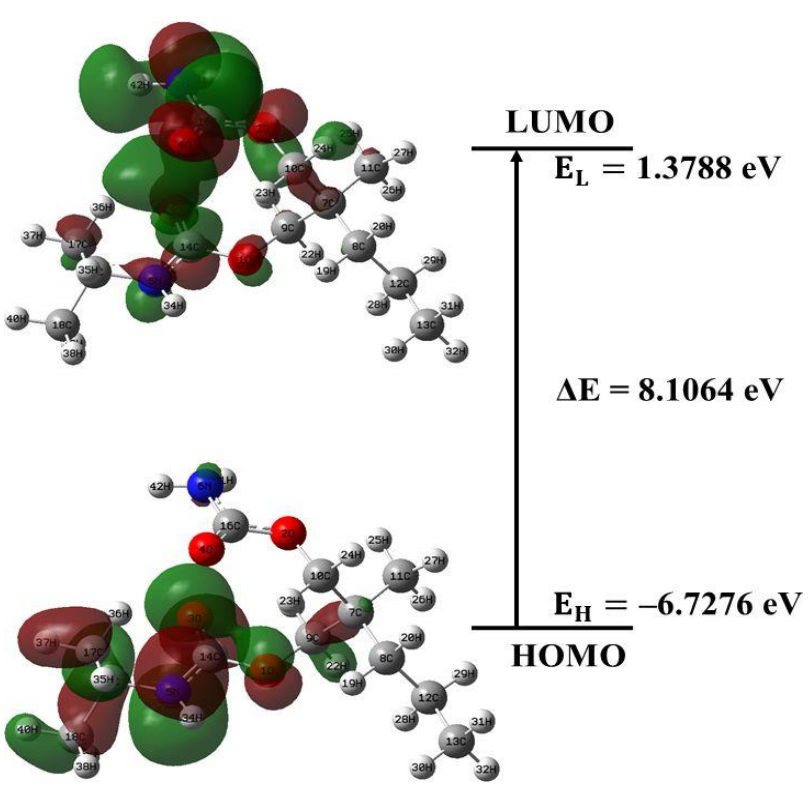

Fig. 3. HOMO and LUMO plot of carisoprodol

\section{Global reactivity}

The high value of $\mu$ and $\omega$ indicates good electrophilic behavior and low-value $\mu$ and $\omega$ indicates nucleophilic behavior of the molecules, respectively (Chaudhary et al., 2020; Joshi, 2017). The electrophilicity index ( $\omega)$ and softness (S) describes the stability of the molecules. The chemical activity increases with a decrease of the energy gap $\left(\mathrm{E}_{\mathrm{L}}-\mathrm{E}_{\mathrm{H}}\right)$ and vice-versa. The values of frontier molecular orbitals (FMOs) energies with their energy gap $\left(\mathrm{E}_{\mathrm{L}}-\mathrm{E}_{\mathrm{H}}\right)$ and parameters; $\chi, \mu, \eta, \omega$ and $\mathrm{S}$ are illustrated in Table 2.

Table 2. Calculated $E_{H}, E_{L}$ energy, band gap $\left(E_{L}-E_{H}\right)$, chemical potential $(\mu)$, electronegativity $(\chi)$, global hardness $(\eta)$, global softness $(S)$, and global electrophilicity index $(\omega)$ for carisoprodol

\begin{tabular}{llllllll}
\hline $\mathrm{E}_{\mathrm{H}}(\mathrm{eV})$ & $\mathrm{E}_{\mathrm{L}}(\mathrm{eV})$ & $\mathrm{E}_{\mathrm{L}}-\mathrm{E}_{\mathrm{H}}(\mathrm{eV})$ & $\chi(\mathrm{eV})$ & $\mu(\mathrm{eV})$ & $\eta(\mathrm{eV})$ & $\mathrm{S}(\mathrm{eV})^{-1}$ & $\omega(\mathrm{eV})$ \\
\hline-6.7276 & 1.3788 & 8.1064 & 2.6744 & -2.6744 & 4.0532 & 0.1234 & 0.8823 \\
\hline
\end{tabular}

\section{Local reactivity}

To explore the quantitative reactive site, the local reactivity descriptors parameters have been calculated. Fukui functions help to predict the particular site for the chemical reactivity. To investigate the particular sites for nucleophilic and electrophilic attack more precisely, we have performed Fukui function analysis. The local reactivity descriptors of the title molecule have been presented the Table 3 . The analysis of local reactivity descriptors shows that the most probable nucleophilic and electrophilic sites of the molecule are C16 and C14, respectively.

\section{Topological analysis (ELF and LOL)}

The density-based description of chemical bonding, the electron localization function (ELF), and the localized orbital locator (LOL) were introduced in literature (Becke \& Edgecombe, 1990; Schmider \& Becke, 2002). The ELF and LOL exhibit similar interpretations based on kinetic energy density in which, electron pair density is considered in ELF, and gradients of localized orbitals were recognized in LOL (Schmider \& Becke, 2000; Rizwana et al., 2020). The values of ELF and LOL fall within the range $0-1$, whereas values greater than 0.5 indicate the region of localized electrons and the values smaller than 0.5 indicate the region for delocalized electrons. The value of ELF is high if Pauli's repulsion is high and vice versa. The localized electrons represent the atomic shells, chemical bonds, and lone pair electrons (Abraham et al., 2018).

The Topological analysis of ELF and LOL of the title molecule based on covalent bonds has been performed 
using Multiwfn software. The ELF and LOL map of electrons are presented in Figs. 4(a) and 4(b), respectively. The region around the hydrogen atom is depicted by the red region (high LOL values) which is due to maximum Pauli repulsion. The red region around $\mathrm{O} 2$ and N5 indicates the presence of localized electron lone pairs. Similarly, the covalent bond region between carbon atoms is characterized by red color showing a high degree of electron localization in that place. On the other hand, the blue ring (low LOL values) region is obtained around the nucleus of $\mathrm{O} 2, \mathrm{C} 7, \mathrm{C} 12, \mathrm{C} 15$, and $\mathrm{N} 5$ which is the region between the inner shell and valence shell showing a very low degree of electron localization in that zones.

Table 3. Calculated local reactivity properties of the selected atoms using Hirshfeld [B3LYP/6-31G (d,p)] derived charges of carisoprodol

\begin{tabular}{|c|c|c|c|c|c|}
\hline Site & $\mathrm{f}_{\mathrm{k}}^{+}$ & Site & $\mathrm{f}_{\mathrm{k}}$ & Site & $\mathrm{f}_{\mathrm{k}}^{0}$ \\
\hline N5 & 0.71809 & $\mathrm{C} 14$ & 0.45364 & $\mathrm{C} 16$ & 0.484545 \\
\hline N6 & 0.54164 & $\mathrm{C} 16$ & 0.4298 & $\mathrm{C} 14$ & 0.462195 \\
\hline $\mathrm{O} 4$ & 0.47303 & $\mathrm{C} 15$ & -0.03689 & $\mathrm{C} 15$ & -0.03287 \\
\hline $\mathrm{O} 3$ & 0.44081 & $\mathrm{C} 7$ & -0.05088 & $\mathrm{C} 7$ & -0.04419 \\
\hline $\mathrm{C} 17$ & 0.39192 & $\mathrm{C} 10$ & -0.06599 & $\mathrm{C} 10$ & -0.05063 \\
\hline $\mathrm{C} 18$ & 0.36003 & C9 & -0.06719 & C9 & -0.05111 \\
\hline $\mathrm{O} 1$ & 0.35283 & $\mathrm{C} 12$ & -0.24017 & N5 & -0.15244 \\
\hline $\mathrm{C} 11$ & 0.34618 & $\mathrm{C} 8$ & -0.24339 & $\mathrm{C} 12$ & -0.2241 \\
\hline $\mathrm{C} 13$ & 0.33921 & $\mathrm{O} 2$ & -0.28615 & $\mathrm{C} 8$ & -0.22981 \\
\hline $\mathrm{O} 2$ & 0.31333 & $\mathrm{O} 1$ & -0.29079 & $\mathrm{O} 1$ & -0.26587 \\
\hline $\mathrm{C} 8$ & 0.23454 & $\mathrm{O} 4$ & -0.32017 & $\mathrm{O} 4$ & -0.26713 \\
\hline $\mathrm{C} 12$ & 0.23021 & $\mathrm{O} 3$ & -0.33656 & $\mathrm{O} 2$ & -0.28333 \\
\hline C9 & 0.06022 & N5 & -0.34209 & $\mathrm{O} 3$ & -0.28569 \\
\hline C7 & 0.05691 & $\mathrm{C} 13$ & -0.34877 & $\mathrm{C} 17$ & -0.32884 \\
\hline $\mathrm{C} 10$ & 0.05691 & $\mathrm{C} 18$ & -0.3557 & $\mathrm{C} 18$ & -0.33597 \\
\hline $\mathrm{C} 15$ & 0.02592 & $\mathrm{C} 11$ & -0.35806 & $\mathrm{C} 13$ & -0.3382 \\
\hline $\mathrm{C} 16$ & -0.49487 & $\mathrm{C} 17$ & -0.36145 & $\mathrm{C} 11$ & -0.34277 \\
\hline $\mathrm{C} 14$ & -0.51843 & N6 & -0.44489 & N6 & -0.38874 \\
\hline
\end{tabular}

\section{Natural bond orbital (NBO) analysis}

NBO analysis is the fundamental tool to interpret the delocalization of charge from donor Lewis type (occupied) orbitals to acceptor Lewis type (unoccupied) orbitals or lone pair to acceptor orbital, within the molecule, to check the stability of the molecular system (Chaudhary et al., 2021c). The stabilization energy $\mathrm{E}(2)$ is determined by the second-order perturbation theory. Higher the value of $\mathrm{E}(2)$, the stronger the interaction between donor and acceptor orbital, and vice versa. For carisoprodol, the NBO analysis has been carried out by B3LYP/6-31G(d,p) and the selected hyper-conjugative interaction of stabilization energy $\mathrm{E}(2)$ greater than 5 $\mathrm{kcal} / \mathrm{mol}$ is presented in Table 4.

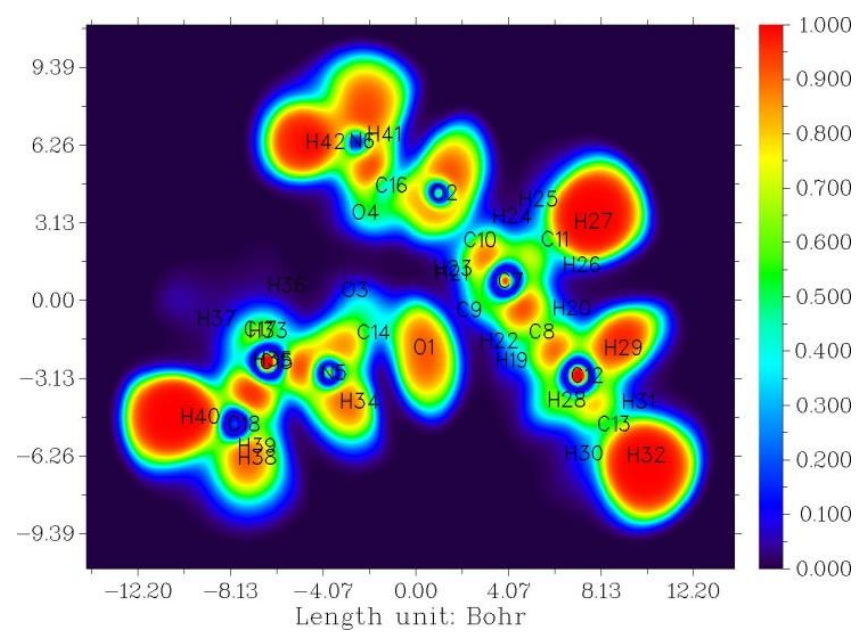

(a)

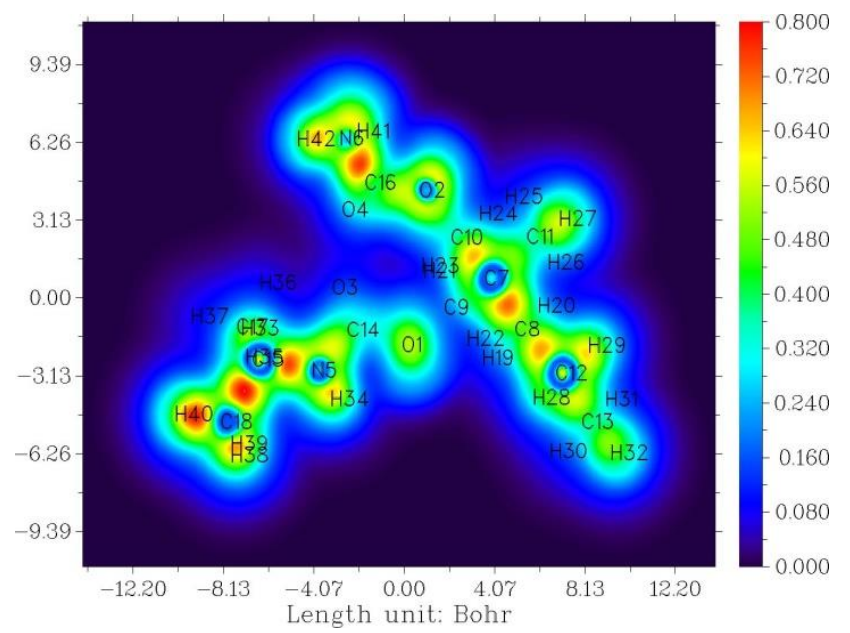

(b)

Fig. 4. ELF color-filled map of carisoprodol (a) and LOL color-filled map of carisoprodol (b)

In the carisoprodol the donor orbitals are generally associated with $\mathrm{O} 1, \mathrm{O} 2, \mathrm{O} 3, \mathrm{O} 4, \mathrm{~N} 5$, and $\mathrm{N} 6$ whereas the acceptor orbitals are mainly concentrated across (O3$\mathrm{C} 14)$, (O2-C16), and (O4-C16). The transition from $\mathrm{LP}(2) \mathrm{O} 1 \rightarrow \sigma^{*}(\mathrm{O} 3-\mathrm{C} 14) / \pi^{*}(\mathrm{O} 3-\mathrm{C} 14)$ stabilizes the molecule with respected energies $6.12 / 19.32 \mathrm{kcal} / \mathrm{mol}$. Similarly, the strongest interaction $\mathrm{LP}(2) \mathrm{O} 4 \rightarrow \sigma^{*}(\mathrm{O} 2-$ C16) gives the highest stabilization energy 33.19 $\mathrm{kcal} / \mathrm{mol}$. Moreover, the transition which participates for the stability of a molecule is $\mathrm{LP}(2) \mathrm{O} 3 \rightarrow \sigma^{*}(\mathrm{O} 1-\mathrm{C} 14)$, $\mathrm{LP}(1) \mathrm{N} 5 \rightarrow \pi^{*}(\mathrm{O} 3-\mathrm{C} 14), \mathrm{LP}(2) \mathrm{O} 2 \rightarrow \pi^{*}(\mathrm{O} 4-\mathrm{C} 16)$, and $\mathrm{LP}(2) \mathrm{O} 4 \rightarrow \sigma^{*}(\mathrm{~N} 6-\mathrm{C} 16)$, with the corresponding stabilization energy 33.02, 26.12, 23.95, and 22.37 $\mathrm{kcal} / \mathrm{mol}$. Also, the overlapping of $\sigma(\mathrm{N} 6-\mathrm{H} 42) \rightarrow \sigma^{*}(\mathrm{O} 2-$ $\mathrm{C} 16)$ and LP(1)N5 $\rightarrow \sigma^{*}(\mathrm{O} 3-\mathrm{C} 14)$ stabilizes the molecule to some extent with interaction energy 5.05 and $9.01 \mathrm{kcal} / \mathrm{mol}$, respectively. 


\section{Molecular docking of carisoprodol}

The molecular docking simulation is a very popular tool to study ligand-protein interaction and to investigate the insight properties of the drug molecule (Chaudhary et al., 2021d). In the present work, to study the biological activities of carisoprodol (ligand), the docking analysis has been conducted by using AutoDock-Vina software.
The target protein, Tyrosine-protein kinase ABL has been predicted with the help of Swiss Target Prediction (Gfeller et al., 2014). It is a human protein that is known to be essential for transforming activity (Buchdunger et $a l .$, 1996). The PDB structure of this protein (1awo) has been downloaded from the RSCB PDB data bank (Rose $e t$ al., 2010). Further, the Ramchandran Plots of the protein have been presented in Fig. 5.

Table 4. Second-order perturbation theory analysis of Fock matrix in NBO basis of carisoprodol

\begin{tabular}{lllllll}
\hline $\begin{array}{l}\text { Donor } \\
\text { NBO(i) }\end{array}$ & ED (i )/e & $\begin{array}{l}\text { Acceptor } \\
\text { NBO(j) }\end{array}$ & ED(j)/e & $\begin{array}{l}\mathrm{E}(2)^{\mathrm{a}} \\
\mathrm{kcal} / \mathrm{mol}\end{array}$ & $\mathrm{E}(\mathrm{j})$-E(i) $)^{\mathrm{b}}$ a.u. & $\mathrm{F}(\mathrm{i}, \mathrm{j})^{\mathrm{c}} \mathrm{a} . u$. \\
\hline$\sigma(\mathrm{N} 6-\mathrm{H} 42)$ & 1.98354 & $\sigma^{*}(\mathrm{O} 2-\mathrm{C} 16)$ & 0.10895 & 5.05 & 1.02 & 0.065 \\
LP(1)O1 & 1.96128 & $\sigma^{*}(\mathrm{O} 3-\mathrm{C} 14)$ & 0.13671 & 6.99 & 0.97 & 0.075 \\
LP(2)O1 & 1.83349 & $\sigma^{*}(\mathrm{O} 3-\mathrm{C} 14)$ & 0.13671 & 6.12 & 0.73 & 0.060 \\
LP(2)O1 & 1.83349 & $\pi^{*}(\mathrm{O} 3-\mathrm{C} 14)$ & 0.27031 & 19.32 & 0.51 & 0.091 \\
LP(2)O2 & 1.82575 & $\pi^{*}(\mathrm{O} 4-\mathrm{C} 16)$ & 0.26555 & 23.95 & 0.49 & 0.099 \\
LP(2)O3 & 1.82617 & $\sigma^{*}(\mathrm{O} 1-\mathrm{C} 14)$ & 0.10898 & 33.02 & 0.60 & 0.128 \\
LP(2)O3 & 1.82617 & $\sigma^{*}(\mathrm{~N} 5-\mathrm{C} 14)$ & 0.06741 & 22.12 & 0.73 & 0.116 \\
LP(2)O4 & 1.83134 & $\sigma^{*}(\mathrm{O} 2-\mathrm{C} 16)$ & 0.10895 & 33.19 & 0.61 & 0.129 \\
LP(2)O4 & 1.83134 & $\sigma^{*}(\mathrm{~N} 6-\mathrm{C} 16)$ & 0.06426 & 22.37 & 0.70 & 0.115 \\
LP(1)N5 & 1.73537 & $\sigma^{*}(\mathrm{O} 3-\mathrm{C} 14)$ & 0.13671 & 9.01 & 0.67 & 0.072 \\
LP(1)N5 & 1.73537 & $\pi^{*}(\mathrm{O} 3-\mathrm{C} 14)$ & 0.27031 & 26.12 & 0.45 & 0.097 \\
LP(1)N5 & 1.73537 & $\sigma^{*}(\mathrm{C} 15-\mathrm{C} 17)$ & 0.02192 & 6.20 & 0.64 & 0.060 \\
LP(1)N6 & 1.79977 & $\sigma^{*}(\mathrm{O} 4-\mathrm{C} 16)$ & 0.11244 & 8.03 & 0.74 & 0.070 \\
LP(1)N6 & 1.79977 & $\pi^{*}(\mathrm{O} 4-\mathrm{C} 16)$ & 0.26555 & 20.26 & 0.46 & 0.088
\end{tabular}

${ }^{a} E(2)$ means the energy of hyper conjugative interaction (stabilization energy); ${ }^{b}$ Energy difference between the donor (i) and acceptor (j) NBO orbitals and ${ }^{c} F(i, j)$ is the Fock matrix element between $i$ and $j \mathrm{NBO}$ orbitals

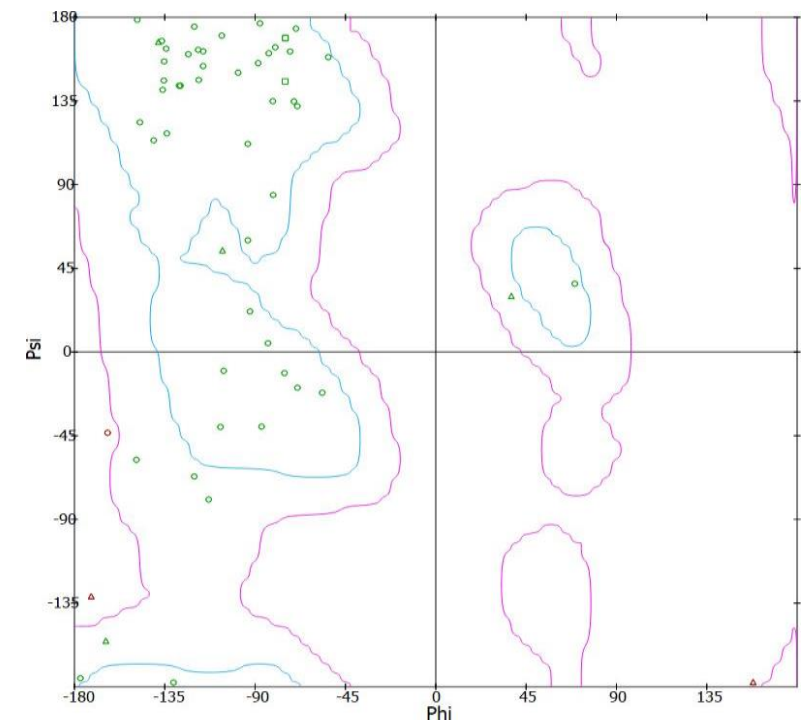

Fig. 5. Ramchandran plot of 1 wao
The regions inside the first blue line indicate allowed ones and those outside it indicate disallowed regions, respectively. Hence, the maximum number of residues lies within the allowed region. The optimized structure of carisoprodol (ligand) obtained at B3LYP/6-31G(d,p) has been used for the docking analysis. The protein (receptor) was prepared by removing water molecules and cocrystallized ligand from the protein and further, the polar hydrogen and Kollman charges were added. The grid box of size $60 \AA \times 60 \AA \times 60 \AA$ has been used for studying the binding activities.

The discovery studio was used for the visualization of ligand-protein interaction. The ligand-protein interaction and LiGPLOT are shown in Figs. 6(a) and 6(b). The binding affinity, bond length, bonded residues, and inhibition constant of the docked complex of carisoprodol and 1 wao have been presented in Table 5. The atoms $\mathrm{O} 1$, $\mathrm{O} 2, \mathrm{O} 3$, and $\mathrm{O} 4$ form six hydrogen bonds with the amino acids SER75, GLY76, ASN78, THR79, THR79, and 
Topological and reactivity descriptor of carisoprodol from DFT and molecular docking approach

THR79. The binding energy of docked structure of the investigated molecule with the protein was found to be -5 $\mathrm{kcal} / \mathrm{mol}$. Hence, carisoprodol shows strong binding activity with the protein 1 wao.

Table 5. The docking parameters of docked structure of carisoprodol and 1wao

\begin{tabular}{|c|c|c|c|c|c|c|c|}
\hline Protein & & $\begin{array}{l}\text { PDB } \\
\text { code }\end{array}$ & $\begin{array}{l}\text { Binding affinity } \\
(\mathrm{kcal} / \mathrm{mol})\end{array}$ & $\begin{array}{l}\text { Bond } \\
\text { length }(\AA)\end{array}$ & $\begin{array}{l}\text { Bonded } \\
\text { Residues }\end{array}$ & $\begin{array}{l}\text { Types of } \\
\text { H-bond }\end{array}$ & $\begin{array}{l}\text { Inhibition } \\
\text { constant }(\mu \mathrm{M})\end{array}$ \\
\hline \multirow{6}{*}{$\begin{array}{l}\text { Tyrosine-protein } \\
\text { ABL }\end{array}$} & \multirow[t]{6}{*}{ kinase } & \multirow[t]{6}{*}{ 1awo } & \multirow[t]{6}{*}{-5.0} & 2.7604 & SER75 & H-bond & \multirow[t]{6}{*}{215.16} \\
\hline & & & & 2.8959 & GLY76 & H-bond & \\
\hline & & & & 2.3335 & ASN78 & H-bond & \\
\hline & & & & 2.3037 & THR79 & H-bond & \\
\hline & & & & 2.2572 & THR79 & H-bond & \\
\hline & & & & 2.7032 & THR79 & H-bond & \\
\hline
\end{tabular}

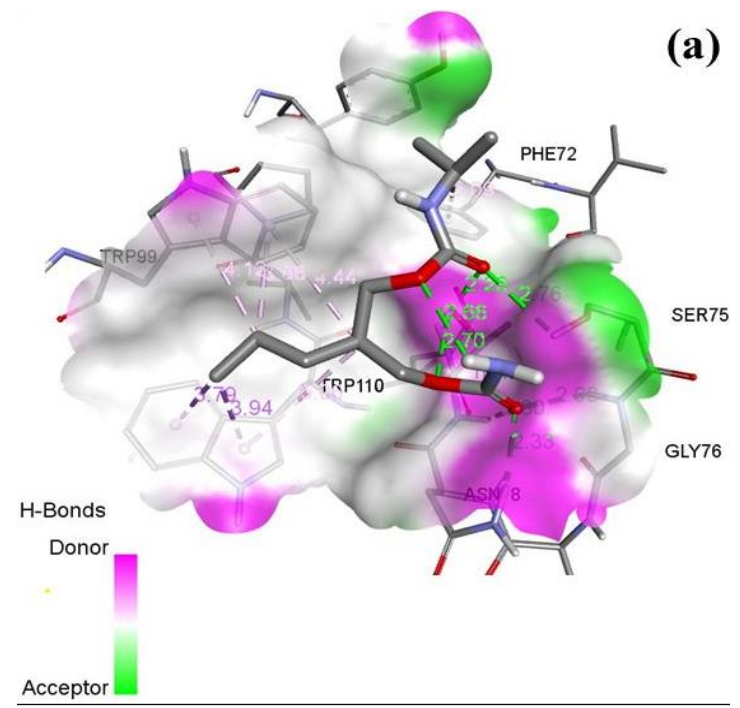

Acceptor

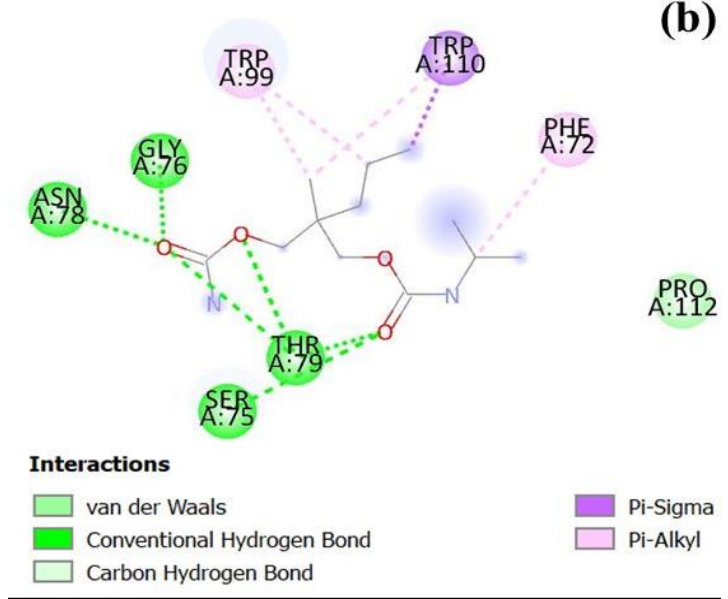

Fig. 6. (a) Docking of carisoprodol with 1wao and (b) LIGPLOT of docking of carisoprodol with 1wao

\section{CONCLUSION}

The optimized geometrical parameters and crystal geometrical parameters of carisoprodol were almost in resonance. The energy gap between HOMO and LUMO was found to be $8.1064 \mathrm{eV}$. Due to the high value of Fukai functions, the nucleophilic and electrophilic sites are predicted as $\mathrm{C} 16$ and $\mathrm{C} 14$, respectively. The molecular electrostatic potential map explorers are the negative and positive potentials associated with the carbonyl and amine groups, respectively. ELF and LOL topological analysis signifies that most of the localized electrons were predicted around hydrogen, oxygen, nitrogen, and between carbon atoms.

Further, the NBO analysis demonstrates the intramolecular charge transfer between lone pair $\mathrm{LP}(2) \mathrm{O} 4$ and $\sigma^{*}(\mathrm{O} 2-\mathrm{C} 16)$, which contribute the highest value of stabilization energy $33.19 \mathrm{kcal} / \mathrm{mol}$. The molecular docking simulation revealed that the carisoprodol strongly binds with the protein 1 wao. Also, the oxygen atom of all carbonyl groups actively participated in hydrogen bonding to form a complex.

\section{ACKNOWLEDGEMENT}

Authors sincerely acknowledge to Prof. Poonam Tandon, HOD Physics and Dean Student Welfare, University of Lucknow, India for providing software facilities including Gaussian 09 as well as sharing research ideas during the project.

\section{REFERENCES}

Abraham, C. S., Prasana, J. C., Muthu, S., \& Raja, M. (2018). Quantum computational studies, spectroscopic (FT-IR, FT-Raman, and UV-Vis) profiling, natural hybrid orbital, and molecular docking analysis on 2, 4 Dibromoaniline. Journal of Molecular Structure, 1160, 393-405.

Becke, A. D. (1993). A new mixing of Hartree-Fock and local density-functional theories. The Journal of Chemical Physics, 98(2), 1372-1377.

Becke, A. D., \& Edgecombe, K. E. (1990). A simple measure of electron localization in atomic and 
molecular systems. The Journal of Chemical Physics, 92(9), 5397-5403.

Bolattin, M. B., Nandibewoor, S. T., Joshi, S. D., Dixit, S. R., \& Chimatadar, S. A. (2016). Interaction between carisoprodol and bovine serum albumin and effect of $\beta$-cyclodextrin on binding: insights from molecular docking and spectroscopic techniques. RSC Advances, 6(68), 63463-63471.

Buchdunger, E., Zimmermann, J., Mett, H., Meyer, T., Müller, M., Druker, B. J., \& Lydon, N. B. (1996). Inhibition of the Abl protein-tyrosine kinase in vitro and in vivo by a 2-phenylaminopyrimidine derivative. Cancer Research, 56(1), 100-104.

Chaudhary, M. K., Chaudhary, T., \& Joshi, B. D. (2021a). Simulated spectra (IR and Raman), NLO, AIM, and molecular docking of carisoprodol from DFT approach. Bibechana, 18(1), 48-57.

Chaudhary, M. K., Karthick, T., Joshi, B. D., Prajapati, P., de Santana, M. S. A., Ayala, A. P., Reeda, V. S. J., \& Tandon, P. (2021b). Molecular structure and quantum descriptors of cefradine by using vibrational spectroscopy (IR and Raman), NBO, AIM, chemical reactivity, and molecular docking. Spectrochimica Acta Part A: Molecular and Biomolecular Spectroscopy, 246, 118976. https://doi.org/10.1016/j.saa.2020.118976

Chaudhary, M. K., Prajapati, P., Srivastava, K., Silva, K. F., Joshi, B. D., Tandon, P., \& Ayala, A. P. (2021c). Molecular interactions and vibrational properties of ricobendazole: Insights from quantum chemical calculation and spectroscopic methods. Journal of Molecular Structure, 1230, 129889. https://doi.org/10.1016/j.molstruc.2021.129889

Chaudhary, M. K., Srivastava, A., Singh, K. K., Tandon, P., \& Joshi, B. D. (2020). Computational evaluation on molecular stability, reactivity, and drug potential of frovatriptan from DFT and molecular docking approach. Computational and Theoretical Chemistry, 1191, 113031. https://doi.org/10.1016/j.comptc.2020.113031

Chaudhary, T., Chaudhary, M. K., Joshi, B. D., de Santana, M. S. A., \& Ayala, A. P. (2021d). Spectroscopic (FT-IR, Raman) analysis and computational study on conformational geometry, AIM and biological activity of cephalexin from DFT and molecular docking approach. Journal of Molecular Structure, 1240, 130594. https://doi.org/10.1016/j.molstruc.2021.130594

Diogo, H. P., Ramos, J. J. M., \& Piedade, M. F. M. (2018). Thermal behavior and dynamic fragility in amorphous carisoprodol. Correlation between the dynamic and thermodynamic fragilities. Thermochimica Acta, 663, 99-109.

Frisch, M. J., Trucks, G. W., Schlegel, H. B., Scuseria, G. E., Cheeseman, J. R., Robb, M. A., \& Fox, D. J., (2009). GAUSSIAN 09, revision, Gaussian, Inc., Wallingford CT.

Fukui, K. (1982). Role of frontier orbitals in chemical reactions. Science, 218(4574), 747-754.

Gfeller, D., Grosdidier, A., Wirth, M., Daina, A., Michielin, O., \& Zoete, V. (2014). Swiss target prediction: a web server for target prediction of bioactive small molecules. Nucleic Acids Research, 42(1), W32-W38

Horio, K., Tanaka, R., Akama, H., Haramura, M., Tanaka, A., Akimoto, T., \& Hirayama, N. (2004). Crystal structure of carisoprodol. Analytical Sciences: X-ray Structure Analysis Online, 20, x43-x44.

Humphrey, W., Dalke, A., \& Schulten, K. (1996). VMD: visual molecular dynamics. Journal of Molecular Graphics, 14(1), 33-38.

Joshi, B. D. (2016). Chemical reactivity, dipole moment and first hyperpolarizability of aristolochic acid I. Journal of Institute of Science and Technology, 21(1), 1-9.

Joshi, B. D. (2017). Structural, electronic and vibrational study of 4, 6-dichloro-5-methyl pyrimidine: A DFT approach. Journal of Institute of Science and Technology, 22(1), 51-60.

Joshi, B. D., Khadka, J. B., \& Bhatt, A. (2018). Structure, electronic and vibrational study of 7-methyl-2, 3dihydro- $(1,3)$ thiazolo $(3,2-\mathrm{A})$ pyrimidine-5-one by using density functional theory. Journal of Institute of Science and Technology, 22(2), 1-11.

Joshi, B. D., Mishra, R., Tandon, P., Oliveira, A. C., \& Ayala, A. P. (2014). Quantum chemical studies of structural, vibrational, NBO and hyperpolarizability of ondansetron hydrochloride. Journal of Molecular Structure, 1058, 31-40.

Kumar, K. A., Lakshmipathi, V. S., Meenakshi, S., \& Balakrishnan, M. H. (2017). Synthesis and characterization of potential impurity of muscle relaxant drug carisoprodol. Journal Chemistry and Chemical Sciences, 7(4), 352-360.

Liu, J., Huang, R., \& Claudio, M. (2020). Determining the binding site of carisoprodol on GABAA receptor. https://hdl.handle.net/20.500.12503/30337

Lu, T., \& Chen, F. (2012). Multiwfn: a multifunctional wave function analyzer. Journal of Computational Chemistry, 33(5), 580-592. 
Parr, R. G., \& Pearson, R. G., (1983). Absolute hardness: companion parameter to absolute electronegativity. Journal of the American Chemical Society. 105(26), 7512-7516.

Parr, R. G., \& Yang, W. (1989). Density-functional theory of atoms and molecules. Oxford University Press, New York Oxford. https://doi.org/10.1002/qua.560470107

Parr, R. G., Szentpály, L. V., \& Liu, S. (1999). Electrophilicity index. Journal of the American Chemical Society, 121(9), 1922-1924.

Prajapati, P., Pandey, J., Shimpi, M. R., Srivastava, A., Tandon, P., Velaga, S. P., \& Sinha, K. (2016). Combined spectroscopic and quantum chemical studies of ezetimibe. Journal of Molecular Structure, 1125, 193-203.

Reed, A. E., Curtiss, L. A., \& Weinhold, F. (1988). Intermolecular interactions from a natural bond orbital, donor-acceptor viewpoint. Chemical Reviews, 88(6), 899-926.

Reeves, R. R., Carter, O. S., Pinkofsky, H. B., Struve, F. A., \& Bennett, D. M. (1999). Carisoprodol (Soma) abuse potential and physician unawareness. Journal of Addictive Diseases, 18(2), 51-56.

Rizwana, B. F., Prasana, J. C., Muthu, S., \& Abraham, C. S. (2020). Vibrational spectroscopy, reactive site analysis and molecular docking studies on 2-[(2amino-6-oxo-6, 9-dihydro-3H-purin-9-yl) methoxy]3-hydroxypropyl (2S)-2-amino-3-methyl butanoate. Journal of Molecular Structure, 1202, 127274.
Rose, P. W., Beran, B., Bi, C., Bluhm, W. F., Dimitropoulos, D., Goodsell, D. S., Prlic, A., Quesada, M., Quinn, G. B., Westbrook, J. D., Young, J., Yukich, B., Zardecki, C., Berman, H. M., \& Bourne, P. E. (2010). The RCSB protein data bank: redesigned website and web services. Nucleic Acids Research, 39(sup. 11), D392-D401.

Schmider, H. L., \& Becke, A. D. (2000). Chemical content of the kinetic energy density. Journal of Molecular Structure: Theochem, 527(1-3), 51-61.

Schmider, H. L., \& Becke, A. D. (2002). Two functions of the density matrix and their relation to the chemical bond. The Journal of Chemical Physics, 116(8), 3184-3193.

Sjoberg, P., Murray, J. S., Brinck, T., \& Politzer, P. (1990). Average local ionization energies on the molecular surfaces of aromatic systems as guides to chemical reactivity. Canadian Journal of Chemistry, 68(8), 1440-1443.

Studio, D. (2009). Version 2.5 guide. San Diego, CA: Accelrys Inc., p. 92121.

Trott, O., \& Olson, A. J., (2010). AutoDock Vina: Improving the speed and accuracy of docking with a new scoring function, efficient optimization, and multithreading. Journal of Computational Chemistry, 31, 455-461.

Yang, W., \& Parr, R. G. (1985). Hardness, softness, and the Fukui function in the electronic theory of metals and catalysis. Proceedings of the National Academy of Sciences, 82(20), 6723-6726. 